\title{
EFISIENSI ENERGI SMART HOME (RUMAH PINTAR) BERBASIS REMOTE RELAY DAN LDR (LIGHT DEPENDENT RESISTANT)
}

\author{
Imam Abdul Rozaq \\ FakultasTeknik, Program Studi Teknik Elektro \\ UniversitasMuria Kudus \\ Email: imam.rozaq@umk.ac.id \\ Noor Yulita Dwi Setyaningsih \\ FakultasTeknik, Program Studi Teknik Elektro \\ UniversitasMuria Kudus \\ Email: noor.yulita@umk.ac.id
}

\begin{abstract}
ABSTRAK
Perkembangan teknologi saat ini sangat berkembang pesat, dan dapat dirasakan dalam dunia industri maupun masyarakat biasa.Dengan memanfaatkan teknologi yang ada sekarang salah satunya adalah remot relay sebagai alat untuk mengendalikan alat rumah tangga seperti lampu, pagar, pintu jendela dan sebagainya.Metode penelitian dalam penelitian ini adalah riset dan pengembangan. Rencana kerja dari alat ini adalah dengan menggunakan dua mode yaitu mode manual dan mode otomatis, dengan perincian cara pengendalian pada masing-masing beban. Pertama untuk lampu pada kondisi otomatis akan menggunakan LDR sehingga tidak perlumenyalakan lampu pada malam hari dan mematikan lampu pada siang hari. Pada kondisi manual pada tombol ditekan pertama untuk menyalakan lampu dan ditekan yang kedua akan mematikan lampu.Hasil penelitian menunjukkan bahwa alat bekerja dengan baik, dimana untuk kondisi kendali otomatis, pada waktu kondisi siang maka lampu akan mati dan kondisi malam lampu menyala, kemudian untuk kondisi kendali manualnya, pada sistem ini dapat dilakukan kendali menggunakan remote sejauh 90 meter. Tingkat efisiensi dengan memanfaatkan sistem ini 53\% lebih efisien dibandingkan dengan tidak memanfaatkan sistem smart home.
\end{abstract}

Kata kunci: effisiensi energi, smart home, remote relay, $L D R$.

\begin{abstract}
The development of today's technology is growing rapidly, and can be felt in industry and ordinary citizens. By leveraging existing technology one of which is the remote relay as a tool to control household appliances such as lights, fences, doors windows and so on. The research method in this study is a research and development. The work plan of this tool is to use two modes, namely manual mode and automatic mode, with the details of how the control on each load. First to the light conditions will automatically use the LDR so no need to turn on the lights at night and turn off the lights during the day. On the condition of the first user on the button is pressed to turn on the light and pressed the latter will turn off the lights. The results showed that the device worked well, which for the automatic control conditions, during daylight conditions then the light will die and the condition of the night lights are on, then for the condition of the manual control, this system can be done using the remote control as far as 90 meters. The level of efficiency by utilizing this system 53\% more efficient than not utilize smart home system
\end{abstract}

Keywords: energy efficiency, smart home, remote relay, $L D R$.

\section{PENDAHULUAN}

Perkembangan teknologi saat ini sangat pesat yang dapat dirasakan oleh dunia insutri maupun rumah tangga. Rumah sekarang bukan hanya berfungsi sebagai tempat tinggal, akan tetapi rumah banyak digunakan sebagai bisnis, baik untuk kos-kosan, kontrakan atau hanya untuk investasi yang dikarenakan kenaikan harga rumah atau tanah semakin hari semakin naik. Salah satu kebutuhan untuk memenuhi kebutuhan rumah adalah listrik. Dengan adanya kenaikan harga listrik di indonesia maka salah satu cara untuk menghemat energi listrik pada rumah tangga yaitu adalah dengan menggunakan teknologi pintar yang dinamakan smart home. Rumah sekarang bukan hanya sekedar tempat tinggal, akan tetapi sekarang rumah banyak digunakan sebagai bisnis, baik itu dikontrakan maupun digunakan sebagai kos-kosan. Sehingga untuk dapat menarik pelanggan itu maka semakin bagus rumah tersebut maka akan semakin banyak yang menyukai rumah tersebut.

Smart Home merupakan sebuah rumah atau bangunan yang dapat meningkatkan efieisensi, kenyamanan dan keamanan dengan menggunakan teknologi secara otomatis.[1][2][4][5][6][8][11]. 
Dengan adanya teknologi smart home salah satunya dengan memanfaatkan teknologi mikrokontroller Atmega 8535 sebagai salah satu komponen penting yang dapat mengendalikan alat listrik rumah tangga seperti lampu, jendela, tirai, pagar dan sebagainya.

\section{METODOLOGI PENELITIAN}

Metode penelitianyang digunakan dalam penelitian ini adalah Penelitian Risetdanpengembangan Dengan langkah-langkah dalam penelitian ini adalah tahap(1) Design Penelitian, yang terdiri dari mempelajari instalasi rumah yang akan dipasang sistem smart home dan mempelajari ketersediaan komponen yang mudah didapat di masyarakat, tahap(2) pembuatan alat, dengan cara menyiapkan alat dan bahan serta merakit untuk membuat alat smart home yang dapat mengendalikan lampu. (3) pengujian alat terdiri dari penentuan beban yang dapat dikendalikan smart home, pengujian kemampuan remote untuk mengendalikan beban, melakukan pengujian terhadap kepekaan cahaya, yang terakhir adalah dengan cara menggabungkan ketiga cara tersebut dalam mengendalikan suatu beban.[3][5][7][10]. Untuk lebih jelas penggunaan mikrokontroller Atmega 8535 dapat dilihat pada gambar 1 .

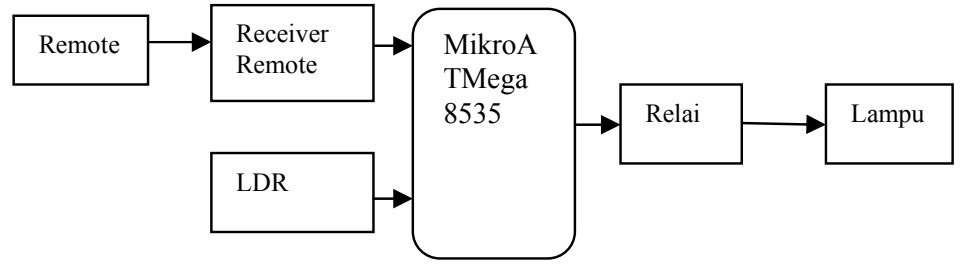

Gambar 1. Skema Rangkaian Electrical Smart Home[10]

Pada gambar 1 dapat dilihat bahwa penggunaan mikrokontroller AT mega 8535 sebagai pengendali relai yang dapat menyalakan lampu berdasarkan masukan dari LDR (Light Dependend Resisstant) dan Receiver Remote. Untuk mengetahui cara kerja dapat dilihat pada gambar 2.

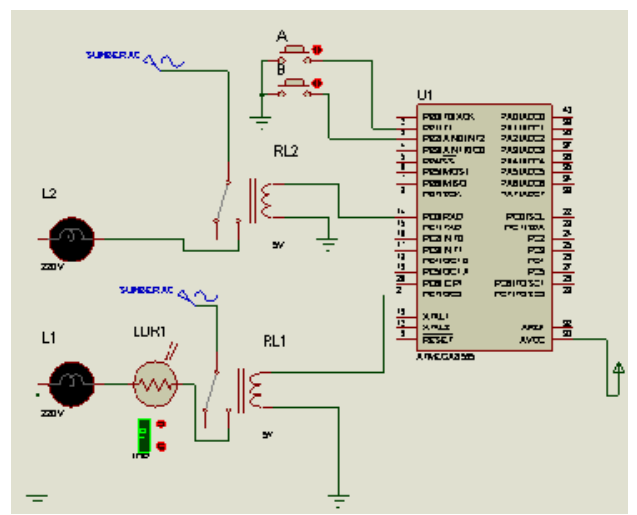

Gambar 2. Rangkaian Pada Mikrokontroller AT Mega 8535[10]

\section{HASIL DAN PEMBAHASAN}

\subsection{Tahap Satu}

Tahap perancangan alat smarthome, dilakukan kegiatansebagai berikut:

1) Mempelajari intalasi rumah yang akan dipasang sistem smarthome yang efektif dan efisien. Dikatakan efektif bila: mudah pengoperasiannya serta dikatakan efisien bila pembuatannya mudah dan murah.

2) Mempelajari ketersediaan bahan baku yang mudah didapat dikalangan masyarakat.

\subsection{Tahap Dua}

Tahap pembuatan alat smarthome, dilakukan kegiatan merakit komponen elektronika yang dibutuhkan.Alat yang gunakan dalam penelitian ini adalah: 


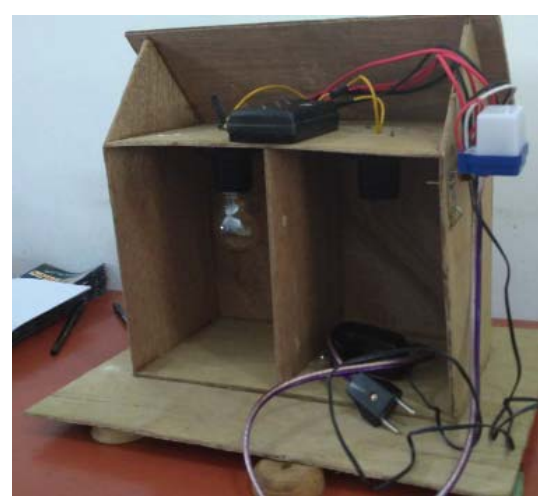

Gambar 3. Tampak Depan Protoype Smart Home[10]

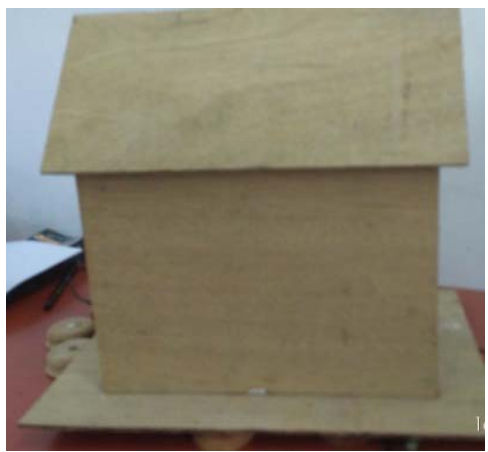

Gambar 5. Tampak Belakang Protoype Smart Home[10]

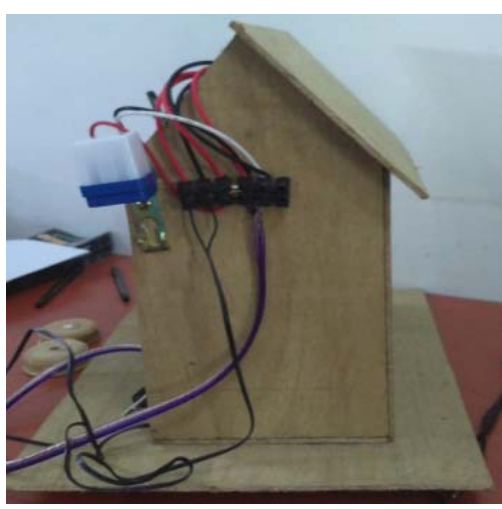

Gambar 4. Tampak Samping Protoype Smart Home[10]

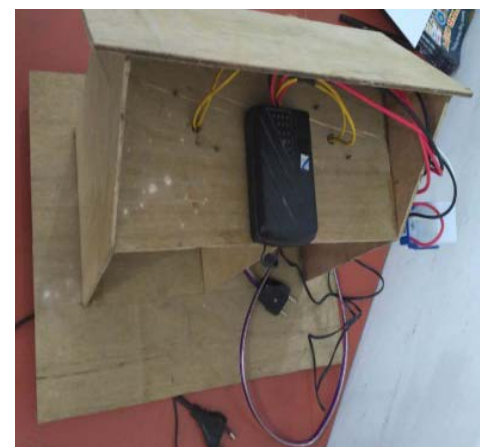

Gambar 6. Tampak Atas Protoype Smart Home[10]

\subsection{Tahap Tiga}

Pengujian alat dilakukan kegiatan sebagai berikut:

1) Hasil Pengujian Sebelum penggunaan Remote Relay dan LDR

Pada analisis dan pembahasan ini akan ditampilkan penggunaan energi sebelum dan setelah menggunakan LDR dan remote Relay. Sebelum menggunakan Remote Relay dan LDR Sebelum menggunakan remote ralay dan LDR data yang didapat adalah tegangan sumber rata-rata adalah 189,6 Volt, arus yang mengalir rata-rata adalah $98,47 \mathrm{~mA}$ sehingga daya yang dihasilkan adalah 18,66 Watt. Untuk lebih jelasnya dapat dilihat pada tabel 1 .

Tabel 1. Penggunaan daya listrik pada siang hari sebelum penggunaan remote relay dan LDR[10]

\begin{tabular}{cccc}
\hline No & Tegangan $(\boldsymbol{V})$ & Arus $(\boldsymbol{m A})$ & Daya $(\boldsymbol{W a t t})$ \\
\hline 1 & 190 & 98,8 & 18,772 \\
2 & 189 & 97,9 & 18,503 \\
3 & 190 & 98,6 & 18,734 \\
4 & 190 & 98,8 & 18,772 \\
5 & 189 & 97,9 & 18,503 \\
6 & 190 & 98,6 & 18,734 \\
7 & 189 & 98,8 & 18,673 \\
8 & 190 & 97,9 & 18,601 \\
9 & 189 & 98,6 & 18,635 \\
10 & 190 & 98,8 & 18,772 \\
Rata-rata & 189,6 & 98,47 & 18,669 \\
\hline
\end{tabular}




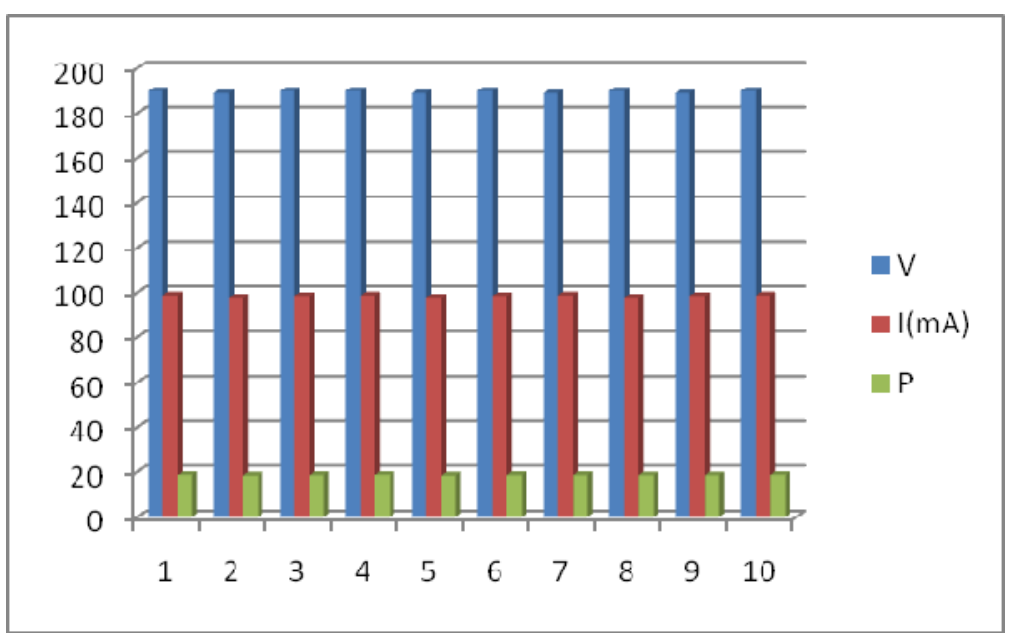

Gambar 7. Hasil Pengukuran Tegangan, Arus dan Daya Kondisi Awal[10]

Pada gambar 7 dapat dilihat bahwa perbandingan pengukuran tegangan, arus, dan daya tidak terdapat perbedaan sehingga dapat dilihat perbulan daya yang digunakan dalam penggunaan lampu adalah 18,66 Watt x 24 jam x 30 hari $=13.435,2$ Watt jam atau 13,4 KWh.

2) Setelah menggunakan Remote Relay dan LDR

Setelah menggunakan remot relay dan LDR peneliti membagi dua bagian daya yang digunakan menggunakan remote ralay dan LDR yaitu data pada siang hari dan data pada saat malam hari.

Data yang didapat pada siang hari adalah tegangan sumber rata-rata adalah 189,6 Volt, arus yang mengalir rata-rata pada siang hari adalah 4,47mA sehingga daya yang dihasilkanpada siang hari adalah 0,84 Watt. Untuk lebih jelasnya dapat dilihat pada tabel 2 dan gambar 11.

Tabel 2. Penggunaan daya listrik pada siang hari setelah penggunaan remote relay dan LDR[10]

\begin{tabular}{cccc}
\hline No & Tegangan $(\boldsymbol{V})$ & Arus $(\boldsymbol{m} \boldsymbol{A})$ & Daya $(\boldsymbol{W a t t})$ \\
\hline 1 & 190 & 4,47 & 0,849 \\
2 & 189 & 4,4 & 0,831 \\
3 & 190 & 4,5 & 0,855 \\
4 & 190 & 4,47 & 0,849 \\
5 & 189 & 4,4 & 0,831 \\
6 & 190 & 4,5 & 0,855 \\
7 & 189 & 4,47 & 0,844 \\
8 & 190 & 4,4 & 0,836 \\
9 & 189 & 4,5 & 0,850 \\
10 & 190 & 4,6 & 0,874 \\
Rata - rata & 189,6 & 4,471 & 0,847 \\
\hline
\end{tabular}

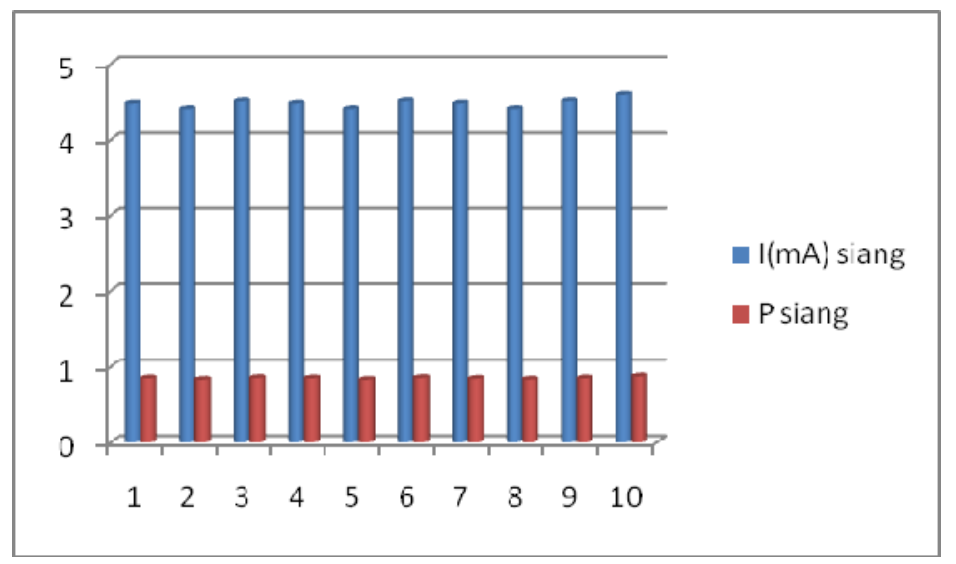

Gambar 8. Hasil Pengukuran I, P pada Siang Hari dengan Sistem Smart Home[10] 
Pada gambar 8. dapat dilihat bahwa perbandingan pengukuran tegangan, arus, dan daya tidak terdapat perbedaan sehingga dapat dilihat perbulan daya yang digunakan dalam penggunaan lampu adalah 0,84 Watt x 12 jam x 30 hari $=302,4$ Watt jam atau $0,3 \mathrm{KWh}$.

Data yang didapat pada siang hari adalah tegangan sumber rata-rata adalah 189,6 Volt, arus yang mengalir rata-rata pada siang hari adalah $102,8 \mathrm{~mA}$ sehingga daya yang dihasilkan pada siang hari adalah 19,5 Watt. Untuk lebih jelasnya dapat dilihat pada tabel dan gambar berikut:

Tabel 3. Penggunaan Daya Listrik pada Malam Hari Sebelum Penggunaan Remote Relay dan LDR[10]

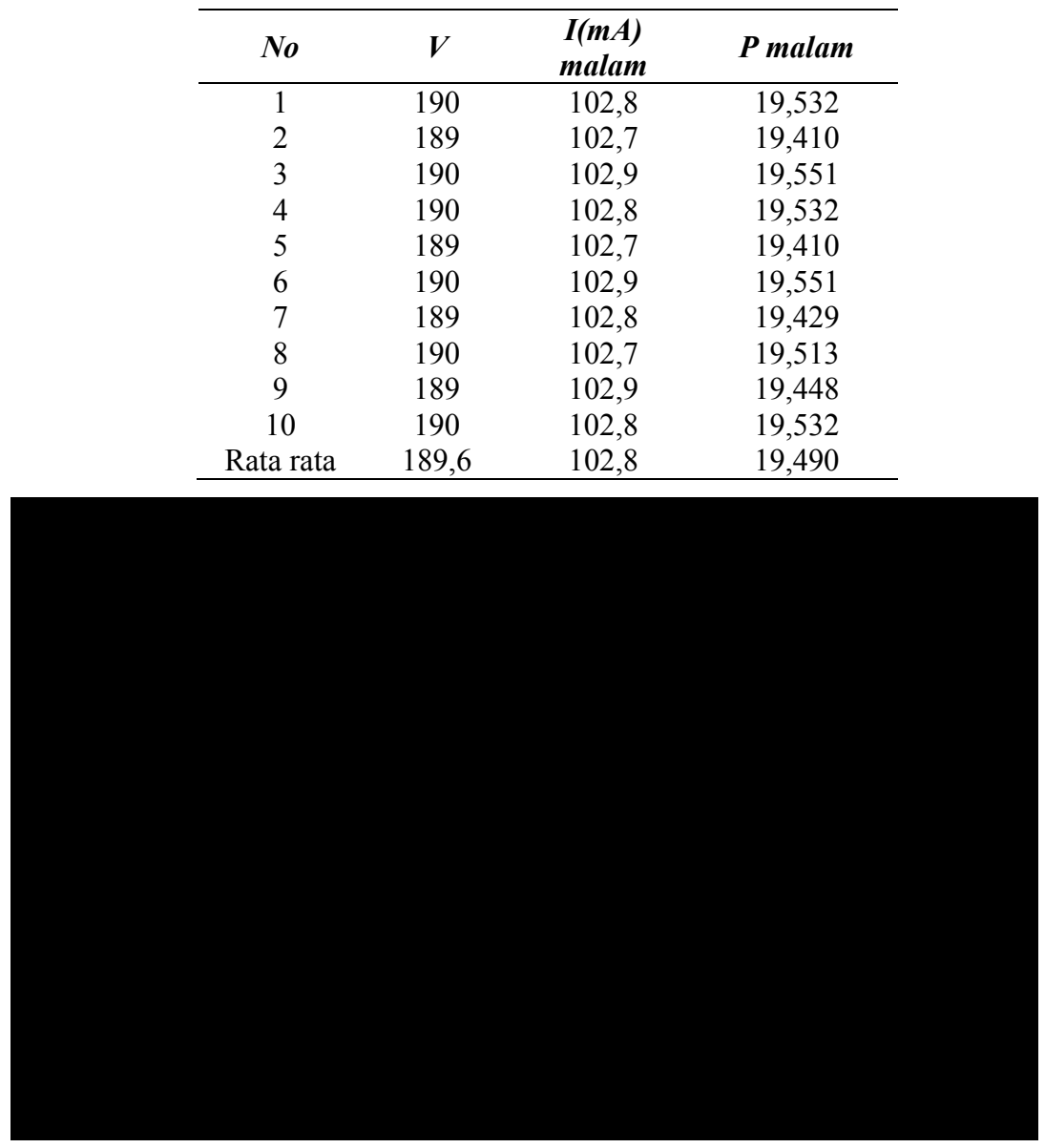

Gambar 9. Hasil pengukuran I, P pada Malam Hari dengan Sistem Smart Home[10]

Pada gambar 9. dapat dilihat bahwa perbandingan pengukuran tegangan, arus, dan daya tidak terdapat perbedaan sehingga dapat dilihat perbulan daya yang digunakan dalam penggunaan lampu adalah 19,4 Watt x 12 jam x 30 hari $=6984$ Watt jam atau 6,9 KWh. Sehingga energi yang digunakan ketika menggunakan remote ralay dan LDR adalah 6,9+0,3=7,2 KWh.

Hasil pada penelitian ini adalah akan membandingkan anatara energi yang digunakan sebelum dan sesudah pemakaian remote relay dan LDR pada smart home. Dari data yang didapat energi sebelum penggunaan remote relay dan LDR adalah 13,4 KWh dan energi setelah penggunaan remote relay dan LDR adalah 7,2 KWh, sehingga efisiensi energi yang didapat adalah:

$$
\begin{aligned}
& \eta=\frac{7,2}{13,4} \times 100 \% \\
& \eta=53 \%
\end{aligned}
$$


3) Pengujian jarak smart home menggunakan remote

Tabel 4. Pengujian jarak prototype smarthome menggunakan remote[10]

\begin{tabular}{ccc}
\hline No & Jarak & Kondisi Lampu \\
\hline 1 & $10 \mathrm{~m}$ & Terkendali \\
2 & $20 \mathrm{~m}$ & Terkendali \\
3 & $30 \mathrm{~m}$ & Terkendali \\
4 & $40 \mathrm{~m}$ & Terkendali \\
5 & $60 \mathrm{~m}$ & Terkendali \\
6 & $80 \mathrm{~m}$ & Terkendali \\
7 & $90 \mathrm{~m}$ & Terkendali \\
8 & $100 \mathrm{~m}$ & TidakTerkendali \\
\hline
\end{tabular}

Dari tabel 4 dapat dilihat bahwa setelah dilakukan beberapa pengujian jarak pengendalian lampu maksimal adalah 90 meter.

\section{KESIMPULAN}

Berdasarkan pengujian yang telah dilakukan dalam penelitian ini dapat simpulkan bahwa:

1) Alat yang dibuat bekerja dengan baik ketika siang lampu mati dan ketika malam lampu menyala serta dapat dikendalikan dengan remote sejauh 90 meter.

2) Efisiensi penggunaan remote relay dan LDR adalah 53\% lebih efisien dibandingkan tanpa menggunakan remote relay dan LDR

\section{DAFTAR PUSTAKA}

[1] Amalia Hanifah dkk, 2010. Aplikasi Smart Card Sebagai Pengunci Elektronis Pada Smart Home. Universitas Diponegoro. Semarang

[2] Ema Irawati dan Firman A, 2010. Perancangan Smart Home Berbasis Programmable Logic Controller. Universitas Gunadarma, Depok

[3] Febri Zahro Aska dkk. Implementasi Radio Frekuensi Identification (RFID) sebagai otomasi pada Smart Home. Universitas Andalas, Padang.

[4] M. Arif Setiawan dkk, 2011. Rancang Bangun Sistem Otomasi Rumah Berasis Mikrokontroler. Proyek Akhir. Politeknik Elektronika Negeri Surabaya, Surabaya..

[5] PPPM, 2012. Panduan Penelitian Dosen Pemula.Politeknik Manufaktur Negeri Bangka Belitung, Bangka Belitung

[6] Pratama, Fajar Niko, 2010. Smart House Berbasis Mikrokontroler AT89S51 via SMS. Skripsi, Universitas Sebelas Maret Surakarta.

[7] PT. Diyen Mandiri, 2015.Teknologi Smart Home Mewujudkan Rumah Impian Anda. http://www.ptdiyen.com/download/general\%20catalogue.pdf. Diakses pada 14 April 2015, $04.54 \mathrm{WIB}$

[8] PT Golden Solution Indonesia. 2015. Home Control. http://www.smarthomeindonesia.co.id/homecontrol/ .Diakses pada 14 April 2015, 04.50 WIB.

[9] ARezkiva, 2012. Perancangan Aplikasi Control dan Monitoring Smart Home Sistem dengan Komunikasi GSM Menggunakan Arduino. Tugas Akhir. Universitas Mercu Buana, Jakarta.

[10] Solekhan, dkk, "Efisiensi Energi Smart Home ( Rumah Pintar) Berbasis Remote Relay Dan LDR (Light Dependent Resistant)". Laporan Penelitian Pemula, Universitas Muria Kudus, Kudus

[11] Fauzan Masykur, Fiqiana Prasetiyowati,"Aplikasi Rumah Pintar (Smart Home) Pengendali Peralatan Elektronik Rumah Tangga Berbasis Web)," Jurnal Teknologi Informasi dan Ilmu Komputer (JTIIK)Vol. 3, No. 1, Maret 2016, hlm. 51-58 